\title{
Increasing the Number of Women Faculty at R1 Schools: Research-based Strategies that Work
} Jenna P. Carpenter

\section{Note: The opinions expressed here are not necessarily those of Notices.}

\section{The Issue}

Despite decades of effort, we still don't attract and retain all of the female faculty talent that exists in fields like mathematics, engineering, and science. But there are things your department can do to change this. There is a large body of research and more than two decades of work by the NSF ADVANCE Program which has shed light on issues related to faculty diversity, along with strategies for addressing them. Campbell University, where I am the founding Dean of the School of Engineering and a past NSF ADVANCE grant principal investigator, is a good example. Today our engineering faculty is $62 \%$ women. Eighty percent of the mechanical engineering faculty are women. One hundred percent of our administrators are women. Compare these percentages to the data for women faculty in mathematics, below, and note that diversity in engineering lags behind that of mathematics. Moreover, our ten faculty in engineering currently are on six National Science Foundation grants totaling $\$ 7.6$ million, and have obtained four additional grants from foundations. Our faculty have won awards for

Jenna P. Carpenter is dean and professor in the School of Engineering at Campbell University. Her email address is carpenter@campbe11.edu.

For permission to reprint this article, please contact: reprint-permission aams.org.

DOI: https://dx.doi.org/10.1090/noti2434 best papers, have obtained competitive fellowships, and have received national recognition for their research.

So what does the research say about how we can increase the number of women faculty in mathematics? One persistent underlying issue is unconscious, implicit, or unintentional bias $[9,11]$. Unconscious bias is just that. It is bias that we all have but of which we are unaware. Research suggests that it comes from stereotypes in our culture (not our identity). That means men and women have similar unconscious biases about women in mathematics.

How exactly does unconscious bias fuel systemic inequities for women faculty in mathematics? One of the reasons that implicit bias is damaging is the fact that it is not intentional. Most people's conscious values support women in mathematics, so people assume that they are treating women fairly. Yet research studies confirm that we engage in many behaviors that treat women unfairly, discourage women, and drive them away from STEM fields like mathematics [11]. We simply are not aware of the collective, real impact of our unconscious biases on our everyday actions, words, attitudes, and decisions. This impact is often described in terms of micro-insults, micro-inequities, and micro-aggressions. Plainly put, these are "small" things that we say and do which suggest that women are not good at math, not interested in math, that it is not appropriate for women to pursue math, and that women don't belong in 
math. Because these things are small when viewed individually, people are tempted to dismiss them as "harmless" or "unimportant." But the collective impact of these daily dings and disses over multiple years is significant. A continual undercurrent of negative behavior creates a chilly and unwelcoming climate for women in mathematics. When it comes to faculty, the collective effect erodes women's authority, power, confidence, and effectiveness in the mathematics workplace. It also erodes our respect for women and view of women as experts in mathematics. So, it shouldn't be a surprise that research shows women in fields like mathematics have to repeatedly prove themselves at work and that they aren't viewed as competent or liked [11]. Yet research also shows that both of these attributes - being viewed as competent and being liked - are important to success in the workplace, influencing favorable evaluations, recommendations for special opportunities, and raises [9]. As a result, qualified women get passed over for scholarships, fellowships, jobs, grants, promotions, administrative and leadership roles, and other opportunities [20]. Virginia Valian, Distinguished Professor at Hunter College and the CUNY Graduate Center, and author of the seminal book Why So Slow: The Advancement of Women [6] refers to this collective impact as the accumulation of disadvantage. This is one of the main reasons that we struggle to attract and retain women faculty in mathematics departments. The farther up the academic ladder we go, the fewer women there are.

\section{Let's Start with the Data}

The Mathematical and Statistical Sciences Annual Survey collects data on the number of male and female faculty, department heads, and assistant/associate/full professors. The most recent data set as of this writing (from 2017-2018) is shown below $[1,2]$ :

\begin{tabular}{|l|l|l|}
\hline & $\begin{array}{l}\% \text { Men } \\
\text { Hired }\end{array}$ & $\begin{array}{l}\% \text { Women } \\
\text { Hired }\end{array}$ \\
\hline Doctoral Math Institution & $72 \%$ & $28 \%$ \\
\hline Masters \& Bachelors Institution & $65 \%$ & $35 \%$ \\
\hline Statistics \& Biostatistics & $67 \%$ & $33 \%$ \\
\hline
\end{tabular}

\begin{tabular}{|l|l|l|}
\hline & $\begin{array}{l}\% \text { Department } \\
\text { Chair - Men }\end{array}$ & $\begin{array}{l}\% \text { Department } \\
\text { Chair - Women }\end{array}$ \\
\hline Math Public & $83 \%$ & $17 \%$ \\
\hline Math Private & $75 \%$ & $25 \%$ \\
\hline Applied Math & $68 \%$ & $32 \%$ \\
\hline Statistics & $80 \%$ & $20 \%$ \\
\hline Biostatistics & $79 \%$ & $21 \%$ \\
\hline Masters Institution & $74 \%$ & $26 \%$ \\
\hline
\end{tabular}

\begin{tabular}{|c|c|c|c|c|}
\hline & $\begin{array}{l}\text { \% Tenured } \\
\text { (Men/ } \\
\text { Women) }\end{array}$ & $\begin{array}{l}\text { \% Full } \\
\text { Professor } \\
\text { (Men/ } \\
\text { Women) }\end{array}$ & $\begin{array}{l}\text { \% Tenure- } \\
\text { Track } \\
\text { (Men/ } \\
\text { Women) }\end{array}$ & $\begin{array}{l}\text { \% Non- } \\
\text { Tenure } \\
\text { Track } \\
\text { (Men/ } \\
\text { Women) }\end{array}$ \\
\hline $\begin{array}{l}\text { Doctoral } \\
\text { Math } \\
\text { Institution }\end{array}$ & $\begin{array}{l}79 \% / \\
21 \%\end{array}$ & $\begin{array}{l}88 \% / \\
12 \%\end{array}$ & $\begin{array}{l}73 \% / \\
27 \%\end{array}$ & $\begin{array}{l}70 \% / \\
30 \%\end{array}$ \\
\hline $\begin{array}{l}\text { Masters } \\
\text { Institution }\end{array}$ & $\begin{array}{l}70 \% / \\
30 \%\end{array}$ & $\begin{array}{l}76 \% / \\
24 \%\end{array}$ & $\begin{array}{l}66 \% / \\
34 \%\end{array}$ & $\begin{array}{l}62 \% / \\
38 \%\end{array}$ \\
\hline $\begin{array}{l}\text { Bachelors } \\
\text { Institution }\end{array}$ & $\begin{array}{l}67 \% / \\
32 \%\end{array}$ & $\begin{array}{l}73 \% / \\
27 \%\end{array}$ & $\begin{array}{l}61 \% / \\
39 \%\end{array}$ & $\begin{array}{l}65 \% / \\
35 \%\end{array}$ \\
\hline $\begin{array}{l}\text { Statistics \& } \\
\text { Biostatistics }\end{array}$ & $\begin{array}{l}66 \% / \\
34 \%\end{array}$ & $\begin{array}{l}78 \% / \\
22 \%\end{array}$ & $\begin{array}{l}66 \% / \\
34 \%\end{array}$ & $\begin{array}{l}53 \% / \\
47 \%\end{array}$ \\
\hline
\end{tabular}

This data shows that women occupy more non-tenure track positions $[1,2]$ more lower-level tenure-track positions [2], and fewer leadership positions [2]. The more prestigious the institution (doctoral versus bachelors, say) the worse the gaps in the data between men and women are. The less applied and interdisciplinary the program (pure mathematics versus biostatistics, say), the worse the gaps in the data are.

\section{Research-based Strategies and Best Practices}

So, what can we do? One area that is ripe for improvement is faculty hiring. Research shows that unconscious bias permeates how we advertise positions, how we form search committees, as well as how we recruit candidates, filter applicant pools, evaluate candidates, and conduct interviews [3]. Fortunately, there is a large volume of research that highlights how unconscious bias negatively impacts recruitment and retention of women faculty, as well as research-based strategies for addressing these problems [11, 19]. There is also a solid body of best practices from other institutions and NSF ADVANCE programs [3, 4, 5] that can be adapted anywhere. It is also important to focus on 
the climate and culture in the department since research shows that unconscious bias continues to impact women after they are hired $[16,17,18]$. Let's start at the beginning, with recruiting new faculty.

\section{Recruiting}

The hiring process starts well before you talk with any candidates. Departments may assume that including the required EEOC statement in their advertisement will be sufficient to attract a more diverse pool of applicants. However, there are many other things you can do to attract a more diverse cohort of applicants. First, make sure that your ad clearly states your commitment to diversity, beyond the required EEOC language. A well-thought-out statement that genuinely reflects your department's and institution's commitment to diversity can help you attract a more diverse applicant pool [19]. Next, faculty position advertisements should avoid a long wish list of desired experience and skills that you really don't expect any single candidate to meet. Why? Research suggests that men tend to overestimate their skills and achievements, so they will apply for a position if they meet most (but not all) of the requirements. They tend to assume that they know enough to get by and can figure out whatever they don't know once they get on the job. Women, on the other hand, tend to undervalue their skills and achievements. Women may underestimate their abilities, predict they won't do well, and don't consider themselves ready for promotions and opportunities [11, 17] even when they are well-qualified. Consequently, women may not apply for a job unless they clearly meet all of the desired skills and experience listed in the ad. Women may assume that these qualifications are just that, minimum requirements for the job. So, instead of that long wish list, state in your advertisement that you are looking for candidates who are interested in an accurate list of required experience and skills. For example, instead of saying that a candidate must have taught course $\mathrm{X}$, say that you are looking for candidates interested in teaching course $\mathrm{X}$. Instead of saying that candidates must work in research area Y, say that you are looking for candidates interested in working in research areas related to Y. These may seem like small changes, but they matter. It means that women candidates are more likely to see themselves as qualified and apply for your position, versus taking themselves out of the pool before they ever apply.

Next, think carefully about the breadth of requirements, experience, and background outlined in your advertisement. Women (due to years of accumulation of disadvantage) often have more varied and less traditional career paths [19]. If your search committee assumes that these women aren't qualified, they will be overlooking some fantastic candidates. Why? Research shows that faculty are poor at predicting who has potential and who does not [7], even though they believe themselves to be skilled at such. Research also suggests that faculty may be biased in favor of candidates from doctoral institutions that are similar to their own, using the prestige of the candidate's doctoral institution as a proxy for the quality of the candidate [19]. Instead of narrow categories of experience and background, focus on broader ranges of experience and expertise that truly are required for the position.

Once you have your written your job ad, do more than just post it in the usual places. If you look where you've always looked, you are likely to find the same type of candidates you've always found. Do targeted recruiting. Reach out to national organizations, like the Association for Women in Mathematics (AMW), and other groups focused on supporting traditionally underrepresented groups in mathematics. Reach out to institutions with LSAMP Programs, GEM consortium institutions, Historically Black Colleges and Universities, Minority-Serving Institutions, and Hispanic-Serving Institutions. Email graduate advisors in $\mathrm{PhD}$ programs and emphasize your interest in attracting diverse candidates. Send your advertisement to women mathematicians at other institutions and ask them to distribute them to their networks. Use a combination of personal emails, advertisements, national organization newsletters, and listserv posts to cast as broad a net as possible [4].

\section{Search Committees}

The next area where unconscious bias plays a large role is with the search committee. The first overarching principle with all of the recommendations is to make sure your search committee and department understand that the goal is to hire the most qualified candidate, not to hire, say, a woman. As we noted above, research shows that because of unconscious bias, faculty are not able to ascertain the most qualified candidate, even though we think that we can [7, $11,20]$. Unless we make a conscious and intentional effort to do otherwise, we tend to hire people who align with our stereotypes. The second overarching principle is to help the search committee and department understand that diversity increases innovation, creativity, productivity, and critical analysis. These attributes position your department to be more successful in teaching, research, and securing grant funding, as well as attracting and mentoring quality graduate students.

Where do we start? First, make sure your search committee is itself diverse. The search committee is a primary source of unfounded bias in searches. A diverse search committee results in more diverse hires [15, 19]. Second, your search committee should complete unconscious bias training before they begin their work, write the advertisement, or look at any applications. Hiring an external expert to do several training sessions with your search committee is a good strategy because training that is poorly done can do more harm than good [19]. Reminding the search committee of potential biases at the evaluation stage can also reduce the impact of bias [19]. Third, appoint a trained 
diversity advocate as a full-fledged member of your search committee [4]. This person should not be a woman faculty member, underrepresented minority faculty member, or staff member. Preferably, the advocate should be someone the department faculty respect and view as having influence. They can help the committee watch out for bias in your discussions, deliberations, language, and decisions. It is a given that your search committee will engage in unconscious bias during the search. A trained diversity advocate can help you catch yourselves and redirect your thoughts and actions to avoid biased decisions and actions.

Next, make sure that your search committee decides on evaluation criteria for the candidates before looking at any applications [19]. These criteria should be the agreed-upon items on which all candidates will be evaluated. Ideally, these criteria should align verbatim with your advertisement (hidden criteria are a major source of implicit bias). Once you have settled on the criteria, create a rubric to be used by every search committee member in evaluating every candidate. Insist that evaluations be backed up with evidence from the application materials (and make sure your rubric includes this evidence) [19]. Search committee members should not use unstated criteria or rationales for evaluating candidates. Why? We filter the applications through our biased lenses, so if we aren't forced to focus on the criteria we agreed upon and the facts from the application materials, bias will sneak in and skew our evaluations [11].

Sound like a lot of work? Yes, it is. But this approach helps your search committee base their evaluations on objective information, versus (unconsciously biased) opinions. It will also help them pick the higher-performing candidate [11], again, because it helps them navigate around the unconscious biases that taint their evaluations. While faculty may insist that they are fair and objective, as we noted above, research studies show that we are not [14]. For example, there are studies where two identical CVs are submitted, the only difference being the candidate's names, and yet the male-named candidate is consistently rated as more qualified than the female-named candidate [18]. Similar studies show that candidates with white-sounding names are rated higher than candidates with ethnic-sounding names [15]. Other research studies have looked at identical application materials for a graduate program. Both men and women faculty at research-intensive institutions rate applicants as significantly more qualified, suggest a higher stipend, and offer more career mentoring to the applicants with male-sounding names versus female-sounding names, even though the application materials were identical aside from the name [11, 18]. Your search committee can avoid these evaluation pitfalls by using stated and agreed upon criteria backed up by observable and documented facts from application materials, all documented in your candidate evaluation rubric. This approach keeps your search committee from (unconsciously) shifting the criteria, and the weight they give to those criteria, to justify their (unconsciously) biased evaluations.

What else can your search committee do to avoid bias? Your committee should be made aware of the fact that letters of recommendation written for men are longer, contain more references to their $\mathrm{CV}$, discuss their publications, and present the candidates as colleagues and researchers. On the other hand, letters of recommendation written for women are shorter, contain more (irrelevant) references to their personal lives (like "she has two kids"), describe women as teachers and students, use fewer standout adjectives, and contain more doubt raisers - hedges, faint praise, and irrelevancies (like "she is friends with my wife") [19]. The search committee also needs to understand that the research on teaching evaluations has found that evaluations are consistently biased in favor of men and against women [12]. In one such study, a male faculty member, Dr. Martin, and a female faculty member, Dr. Mitchell, each taught sections of the same online course. The courses were identical except for the instructor. The male faculty member received higher evaluations in every category, including non-instructor specific categories like course materials and technology that were unrelated to the instructor's demeanor, ability, or attitude [12].

Another key to avoiding bias is to make sure your search committee takes their time when reviewing applications. Research shows that when faculty hurry through reviewing CVs, applications, or grant proposals, they have to rely on mental shortcuts (in order to go faster) and these mental shortcuts rely on unconscious biases and their associated stereotypes [10]. When faculty take their time, they are less likely to be biased. Lastly, when it comes to creating short lists of candidates, start with an empty short list. Then have the search committee go through the list of candidates and look for reasons to put candidates onto the short list, instead of looking for reasons to toss their names out of the pool. Again, this is a small change in thinking but one that makes a difference. It helps us retain candidates who look interesting versus throwing them out because we haven't rated them as perfect. Because our unconscious biases lead us to devalue women's contributions, intelligence, potential, and accomplishments [8], this approach helps short-circuit some of our biased assessments. While it may seem unsurprising, research suggests that when we have a more diverse short list, we are more likely to hire diverse candidates [19].

\section{Interview Process}

Let's assume that you have successfully advertised and selected a more diverse candidate pool using the research-based best practices above. What about the interview process? Be sure to use clear, proactive communication throughout the entire interview (and hiring) process. Use the same (think template) communication with every candidate (to avoid unintentionally biased responses). 
Structured elements help you avoid bias. These include informing all candidates about institutional policies, like spousal hiring, modified duty policies, and family leave policies, as well as information on local schools, as part of the interview. Don't make candidates ask questions about these items. Don't make assumptions about what candidates may or may not be interested in. And when you bring candidates to campus, make sure they have an opportunity to get to know the campus community and interact with people outside your department who are not on your search committee. It gives candidates a chance to ask questions about the department, the institution, and the community that might impact their decision to accept a position but that they might not feel comfortable asking you. What is the reputation of the department elsewhere on campus? How robust is the institution's budget? How good are the local schools?

Another way to use a structured approach is to create a standard, comprehensive offer package before you decide on your final candidates. Do not offer candidates the bare minimum and expect candidates to negotiate to get more. Why? When you hire a candidate, you have your best opportunity to secure for them a competitive salary and the resources they need to be successful. It is unwise to try to hire a candidate as cheaply as possible and think that a windfall will arrive in your department budget down the road. What kind of message are you sending to your prime candidate when you make a poor offer? Also don't insist that your candidate negotiate with you to get better terms. As a society, we tend to regard negotiation as an appropriate activity for men. The result is that male candidates tend to be more experienced negotiators, they are more likely to have mentors who can advise them on how and what to negotiate for, and we tend to respond more positively to men's efforts to negotiate. On the other hand, in our culture it is viewed as socially inappropriate for women to negotiate. Therefore, women tend to reach adulthood with less experience in negotiation and are hesitant to do so. Also, because there are fewer senior women in mathematics, women candidates are less likely to have a woman mentor to advise them on how to negotiate, and they are less likely to know what they can ask for, and how and when to ask. And even if women do try to negotiate, we are not likely to respond to them favorably because they are acting against our stereotype of appropriate female behavior $[13,16]$. Research suggests that this difference in negotiation is one of the reasons that women faculty make less money than comparable men faculty and that female hires are less successful [16]. If we don't give tenure-track faculty the resources and support they need to meet the goals and expectations we have for them, then we shouldn't be surprised if they don't succeed.

\section{After the Hire}

It isn't enough to focus solely on hiring. Unconscious bias continues to impact women after they are hired [11]. Unchecked bias can create a general culture and a climate that ranges from unwelcoming and unsupportive to outright hostile. Therefore, it is crucial to make sure that you follow up all of your hard work during the search and hiring process with strategies to reduce the impact of unconscious bias after the hire. For all of the reasons noted above, unconscious bias influences how we make teaching assignments and utilize teaching evaluations, distribute resources, provide support, and offer opportunities, as well as to our tendency to overburden women with low value service activities. Research shows that academia is based on a masculinized model of success that tends to be competitive and hierarchal, versus collaborative and egalitarian [13]. This lends itself to an unsupportive climate for many faculty. To address this means you will have to meaningfully engage your department in finding better ways to support and mentor all of your faculty. A large number of research-based strategies and practical advice for improving your workplace climate, such as addressing unconscious bias, offering bias training, creating a sense of belonging, using fair and consistent management practices, and promoting diversity can be found in [11].

\section{Conclusion}

We can make real progress in diversifying our faculty. There is no shortage of research-based best practices and resources to help us navigate around our biases and do a more successful job of recruiting and evaluating candidates and mentoring faculty. But if we want to hire and retain a more diverse and qualified faculty, we have to be intentional and proactive. We have to be willing to devote the time, effort, and resources necessary to address the issues. Once we do, we are likely to find that our department is not only more diverse, but also a more supportive, innovative, and pleasant place for everyone to work. This, in turn, will help us attract and retain even more diverse and outstanding faculty in the future.

\section{References}

[1] A. L. Golbeck, T. H, Barr, and C. A. Rose, Report on 2017 2018 Academic Recruitment, Hiring and Attrition, Notices of the American Mathematical Society 67 (2020), no. 2, 235-239.

[2] A. L. Golbeck, T. H. Barr, and C. A. Rose, Fall 2018 Departmental Profile Report, Notices of the American Mathematical Society 67 (2020), no. 10, 1615-1621.

[3] K. O'Meara and D. Culpepper, How Bias Emerges in Academic Hiring: A Research Brief for Faculty Search Committees, Inclusive Hiring Pilot Materials, ADVANCE Program, University of Maryland College Park. https://www.advance . umd.edu/sites/advance. umd .edu/fi les/5.\%20Bias\%20 in\%20Hiring\%20Handout.pdf 
[4] Guide to Best Practices in Faculty Search and Hiring Columbia University. https://provost.columbia.edu /sites/default/files/content/BestPracticesFacu1ty SearchHiring.pdf

[5] Handbook (and toolkit) of Best Practices for Faculty Searches - University of Washington. https://www . washington .edu/diversity/faculty-advancement /handbook/

[6] V. Valian, Why So Slow? The Advancement of Women, MIT Press, Cambridge, Massachusetts, 1999.

[7] C. Wenners and A. Wold, Nepotism and sexism in peer-review, Nature 387 (1997), 341-343.

[8] M. E. Heilman, A. S. Wallen, D. Fuchs, and M. M. Tamkins, Penalties for success: Reaction to women who succeed in male-gender-typed tasks, Journal of Applied Psychology 89 (2004), no. 3, 416-427, DOI 10.1037/0021-9010.89.3.416.

[9] J. C. Williams, The 5 Biases Pushing Women Out of STEM, Harvard Business Review, March 24, 2015.

[10] M. Bendick, Jr., and A. P. Nunes, Developing the research basis for controlling bias in hiring, Journal of Social Issues 68 (2012), no. 2, 238-262, DOI 10.1111/j.15404560.2012.01747.x.

[11] C. Corbett and C. Hill, Solving the Equation, AAUW, Washington, DC, 2015.

[12] K. M. W. Mitchell and J. Martin, Gender Bias in Student Evaluations, Political Science and Politics 51 (2018), no. 3, 648-652, DOI 10.1017/S104909651800001X.

[13] C. Pritlove, C. Juando-Prats, K. Ala-Ieppilampi, and J. A. Parsons, The good, the bad, and the ugly of implicit bias, The Lancet 399 (2019), no. 10171, 502-504, DOI 10.1016/ S0140-6736(18)32267-0.

[14] K. S. Lyness and M. S. Heilman, When fit is fundamental: Performance evaluations and promotions of upper-level female and male managers, Journal of Applied Psychology 91 (2006), no. 4, 777-785, DOI 10.1037/0021-9010.91.4.777.

[15] M. Asplund and C. G. Welle, Advancing Science: How Bias Holds Us Back, Neuron 99 (2018), no. 4, 635-639, DOI 10.1016/j.neuron.2018.07.045.

[16] L. Babcock and S. Lacschever, Women don't ask: Negotiation and the gender divide, Princeton University Press, Princeton, NJ, 2003.

[17] A. Bandura, Self-efficacy mechanism in human agency, American Psychologist 37 (1982), no. 2, 122-147, DOI 10.1037/0003-066x.37.2.122.

[18] R. E. Steinpreis, K. A. Anders, and D. Ritzke, The impact of Gender on the Review of the Curricula Vitae of Job Applicants and Tenure Candidates: A National Empirical Study, Sex Roles 41 (1999), no. 7-8, 509-528, DOI 10.1023/A:1018839203698.

[19] K. O'Meara, D. Culpepper, and L. Templeton, Nudging Toward Diversity: Applying Behavioral Design to Faculty Hiring, Review of Educational Research 90 (2020), no. 3, 311-348, DOI 10.3102/0034654320914742.

[20] E. Reuben, P. Sapienza, and L. Zingales, How Stereotypes Impair Women's Careers in Science, Proceedings of the National Academy of Sciences 111 (2014), no. 12, 44034408, DOI 10.1073/pnas.1314788111.

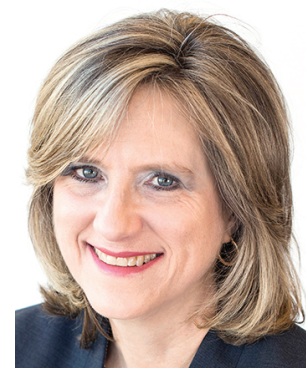

Jenna P. Carpenter

\section{Credits}

Author photo is courtesy of Campbell University.
LEARN ABOUT

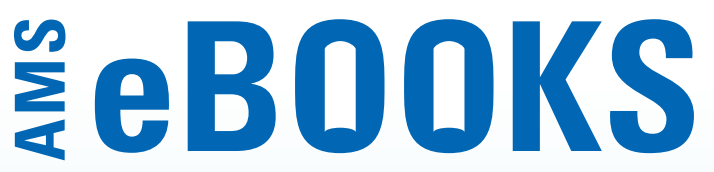

Did you know that most of our titles are now available in eBook form?

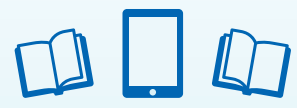

Browse both our print and electronic titles at bookstore.ams.org.

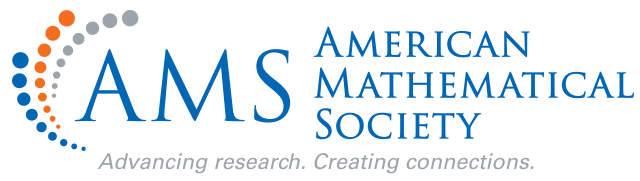

